\title{
Spatial and Temporal Variations of Sound in an Andean City: Cajamarca, Peru
}

\author{
Kent, Robert B., Prof. Dr., University of Akron, Department of Geography and \\ Planning, Akron, Ohio 44325-5005, USA
}

\begin{abstract}
This study provides a preliminary examination of the temporal and geographic variations of sound in Cajamarca, a provincial city in the Andes of northern Peru. Sound levels were sampled in four neighborhoods of the city each representing different land-use characteristics and hypothetically distinct environmental sound profiles. The sample sites included the central plaza, the business district, a residential neighborhood, and a small residential community on the urban periphery. Sound readings were taken each hour between $6 \mathrm{am}$ and $12 \mathrm{pm}$ on every day of the week. Sound profiles for each location for a weekday, a Saturday, and a Sunday are presented. Distinct decibel profiles emerge, both geographically and temporally. These changing sound patterns reflect the activities of the town's residents as they move between home, work, and social/recreational activities during the course of a week. Cajamarca's sound profiles are believed to be characteristic of other provincial cities throughout the Andean region.
\end{abstract}

\section{Introduction}

As a component of the urban milieu in developing countries, the study of sound has received little scholarly attention. Brief studies documenting temporal and geographical variations in sound levels have been conducted in Bangalore, India (Noble et al. 1985) and in Guangzhou, China (Noble 1980). In a related vein traffic sound and human response to it has been documented in three residential neighborhoods representing different socio-economic status in Trinidad, West Indies (Underwood and Boodlal 1983). In Lima, Peru an unpublished study has documented decibel levels along major arterial transport routes at peak traffic hours for 19 different sites in 1970 and 1973 (Ugarte Chamorro 1977). This paper aims to add to the limited body of knowledge on the temporal and geographical characteristics of urban sound in cities in the developing world. It reports on sound variations in Cajamarca, Peru.

Cajamarca is a medium-sized city in the Andes of northern Peru. It has been an important urban place since pre-Hispanic times, and it was here that the Spanish conquistador, Pizarro captured and ransomed Atahuallpa, the Inca emperor, in 1533. Today, it is the department capital of the Department of Cajamarca and is a major economic and administrative center in the northern Andean region, with a population between 75,000 and 85,000 . The city is typical of a whole range of intermediatesized urban centers characteristic of the Andes ranging from Colombia, through Ecuador, Peru, Bolivia, and into northern Argentina.

The study anticipates that the sound profiles for Cajamarca will mirror the daily patterns of human activity in the city. Specifically, it is anticipated that the weekday sound profiles should illustrate the characteristic pattern of morning travel from home to work, a return home during the long midday meal break generally from 1 to $3 \mathrm{pm}$, and then the afternoon return to work and the early evening return home. Sound profiles for weekend days are expected to reveal distinct patterns. Considerable commercial activity does occur on Saturday mornings and the town's principal market day is also on Saturdays, but afternoons are characterized by a notable reduction in business activity and a corresponding reduction in pedestrian and vehicular traffic. Sundays are expected to demonstrate considerably lower levels of sound than weekdays or Saturdays, especially during the morning hours. But, as socializing and family visits are common on Sundays, decibel levels should be higher on Sunday afternoons. 


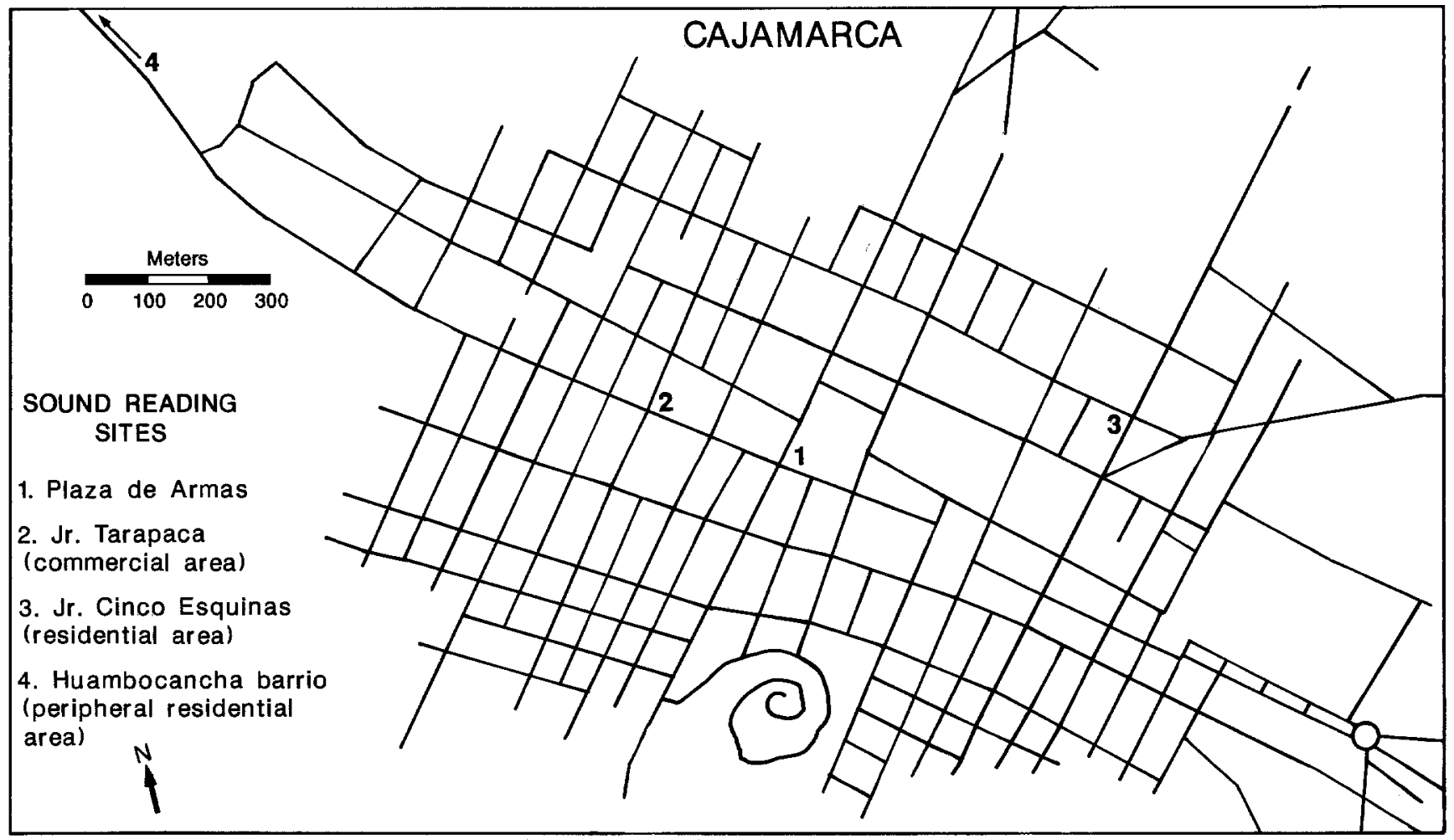

Fig 1 Sound recording sites in Cajamarca, Peru

\section{Methodology}

Sound readings were taken in four different areas of Cajamarca, each representing a distinct land-use type or category (Fig 1). One set of decibel readings were taken on the town's central plaza, the plaza de armas. The central plaza is situated at the geographic center of the city and represents the focus of much of the city's social and economic activity. Two churches front on the plaza, as do several large restaurants, the town's principal hotel, the national telephone and telegraph exchange, the offices of the prefect and police forces, and number of commercial shops. Considerable vehicle and foot traffic also pass through the plaza. Readings were taken in the northwest corner of the plaza.

A second set of readings were recorded along one of the city's major commercial arteries, Jirón Lima (Lima Street) at the intersection with Jirón Tarapacá. This intersection lies two blocks to the northwest of the plaza de armas in an area of concentrated commercial activity. Retail shops, banks, small restaurants, and some offices are located along this street and in the vicinity of the sampling site. Two- and three-story buildings dominate the street. The decibel readings here were taken on the southeast corner of the intersection.

A third set of sound readings were taken in an established residential neighborhood with modest homes in the southeast section of the city at the corner of Jr. (Jirón) Cinco Esquinas and Jr. Leticia. Although this neighborhood is dominated by residential land-uses, a small neighborhood grocery is located across the street from the sampling site, and a small bakery and small evangelical church are each located about one-half block from where the decibel readings were taken. Most structures in this neighborhood are two-story construction. The decibel readings were recorded on the northwest corner of the intersection.

A final set of sound readings were taken a peripheral barrio (neighborhood), Huambocancha. It is located along the principal highway leading north out of the town toward the provincial capitals of Bambamarca and Chota. It represents a mix of rural and urban characteristics. While the narrow strip along the highway is occupied by residential structures and a few petty commercial enterprises, land-uses behind this narrow margin are decided rural with small cultivated fields and grazing areas. Most residents, however, are employed or engaged in urban related occupations. The decibel readings were taken on the west side of the highway and on the north end of the barrio.

Sound readings were recorded at each of the four sites during June and July 1985. The instrument used to take the readings was a GenRad 1565-B Sound-Level Meter. Readings were taken for every day of the week and for 
every hour, usually at the top of the hour, between 6 am and $12 \mathrm{pm}$. Ten readings were taken for each hour at ten second intervals. Only one set of readings were taken for each hour at each site for each day. Readings were not all taken on the same date. Thus, the sound profiles which are presented represent composites. Sound profiles for each of the four sites are presented for weekdays (a summary of the Monday through Friday profiles), Saturday, and Sunday. Average hourly decibel levels were calculated using the logarithmic averaging protocol.

\section{Results}

Weekday Sound Profiles

Sound levels varied considerably among the four sites on weekdays. The patterns of environmental sound were most consistent in the center of the city, along the principal commercial strip and in the plaza central where decibel levels varied less than $10 \mathrm{dBA}$ between the early morning hours and the evening. The highest consistent decibel levels were recorded in the commercial core of the city at the corner of Jr. Lima and Jr. Tarapacá (Fig 2). Readings at this site averaged near $70 \mathrm{dBA}$ throughout most of the day, with a mid-morning peak around $10 \mathrm{am}$. Sound levels dropped off slightly between 2 and $4 \mathrm{pm}$, and then increased marginally through the late afternoon and early evening. Decibel levels dropped to about $65 \mathrm{dBA}$ between 9 and $10 \mathrm{pm}$, and then fell precipitously to about $42 \mathrm{dBA}$ at midnight.

Despite a central location and considerable vehicular and pedestrian traffic, sound levels in the central plaza averaged about $10 \mathrm{dBA}$ lower than those recorded in the commercial area of the city on Jr. Tarapacá. During most of the day decibel levels recorded in the plaza varied between 55 and $65 \mathrm{dBA}$. Early morning decibel levels averaged around $60 \mathrm{dBA}$, climbing slowly during the course of the morning to a high of about $65 \mathrm{dBA}$ at $1 \mathrm{pm}$. Decibel levels dropped about $5 \mathrm{dBA}$ after $1 \mathrm{pm}$ and then remained constant at about $60 \mathrm{dBA}$ until $9 \mathrm{pm}$, and then declined sharply to $45 \mathrm{dBA}$ at midnight.

A much more varied pattern of ambient sound is apparent in Cajamarca's residential neighborhoods. For much of the day at the recording site on Jr. Cinco Esquinas and Jr. José Sabogal, decibel levels ranged between 60 and $70 \mathrm{dBA}$. Early in the day decibel levels peaked at 6 and $8 \mathrm{am}$ at about $70 \mathrm{dBA}$, then dropped off to about $65 \mathrm{dBA}$ throughout the rest of the morning and into midday. A slight drop in sound levels at $2 \mathrm{pm}$ to about $60 \mathrm{dBA}$ corresponds with the time most residents take their midday meal. Decibel levels rise again during the afternoon, peaking at $6 \mathrm{pm}$ at $71 \mathrm{dBA}$. A steady decline in decibel levels occurs throughout most of the evening dropping to about $50 \mathrm{dBA}$ by $10 \mathrm{pm}$ and $45 \mathrm{dBA}$ by midnight.

In Huambocancha, the residential barrio on the northern margins of Cajamarca's urban area, sound levels
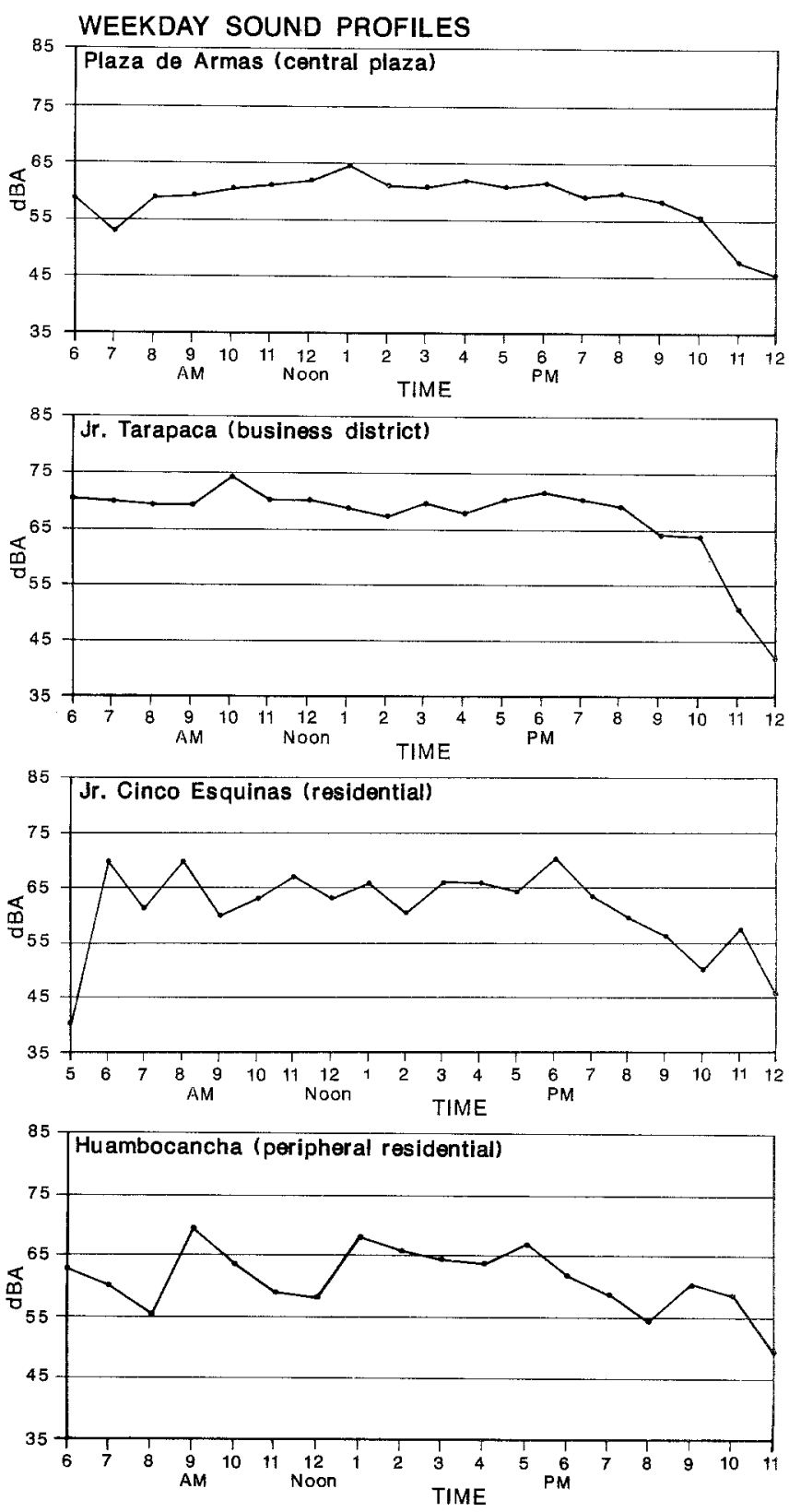

Fig 2 Weekday sound profiles, Cajamarca, Peru

vary throughout the day more than at the other recording sites. Decibel levels are fairly high in the early morning hours, standing at about $63 \mathrm{dBA}$ at $6 \mathrm{am}$. The decibel level then dropped sharply falling to $55 \mathrm{dBA}$ by $8 \mathrm{am}$, but spiked immediately thereafter reaching a daily high of about 70 $\mathrm{dBA}$ at $9 \mathrm{am}$. Sound levels fell off again throughout the remainder of the morning dropping more than $10 \mathrm{dBA}$ to 57 $\mathrm{dBA}$ by noon. But decibel levels rise again in the afternoon and hold fairly steady at about $65 \mathrm{dBA}$ until sometime between 5 and $6 \mathrm{pm}$ when they drop slowly through the 
SATURDAY SOUND PROFILES
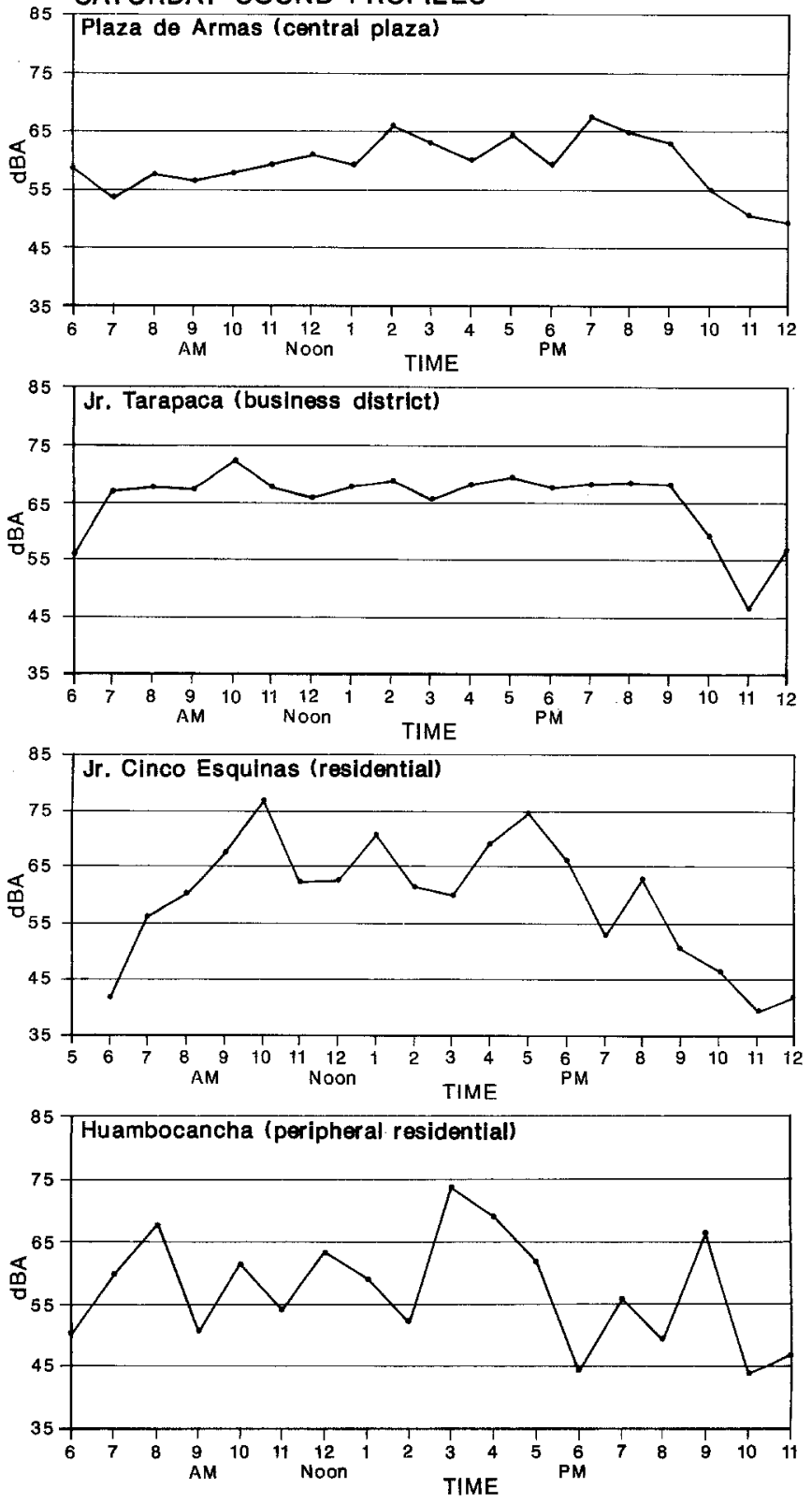

Fig 3 Saturday sound profiles, Cajamarca, Peru

early evening hours to about $55 \mathrm{dBA}$ at $8 \mathrm{pm}$. After a rise of about $5 \mathrm{dBA}$ between 9 and $10 \mathrm{pm}$, decibel levels decline again to about $48 \mathrm{dBA}$ at $11 \mathrm{pm}$.

\section{Weekend Sound Profiles - Saturday}

At the two recording sites in the urban core, Jr. Tarapacá and the central plaza, sound levels on Saturdays demonstrate fairly constant patterns with relatively little variation in decibel levels throughout the day (Fig 3). At Jr. Tarapacá in the city's commercial district decibel levels varied no more than $8 \mathrm{dBAs}$ between $7 \mathrm{am}$ and $9 \mathrm{pm}$, ranging from a high of about $73 \mathrm{dBA}$ at 10 am to a low of 65 $\mathrm{dBA}$ at $3 \mathrm{pm}$. Sound levels fall off quickly after $9 \mathrm{pm}$, dropping to $46 \mathrm{dBA}$ by $11 \mathrm{pm}$.

The temporal pattern of Saturday sound levels at the central plaza displays slightly more variation than that at Jr. Tarapacá. Early morning decibel levels are low, $54 \mathrm{dBA}$ at 7 am, and then climb slowly throughout the morning to between 58 and $61 \mathrm{dBA}$ between 12 noon and $1 \mathrm{pm}$. Sound levels rise somewhat in the afternoon peaking at $65 \mathrm{dBAs}$ at $2 \mathrm{pm}, 5 \mathrm{pm}$, and $7 \mathrm{pm}$. Decibel levels remain high between 7 and $9 \mathrm{pm}$, and then drop off quickly after $9 \mathrm{pm}$ and settling at around $48 \mathrm{dBA}$ at midnight.

The sound levels at the residential sites demonstrate much greater variation from hour to hour and are also characterized by a significantly wider range of decibel readings. At Jr. Cinco Esquinas decibel levels rise steeply during the morning hours, from around $43 \mathrm{dBA}$ at $6 \mathrm{am}$ to over $75 \mathrm{dBA}$ by $10 \mathrm{am}$. Sound levels then drop, peak again at $1 \mathrm{pm}$ at about $70 \mathrm{dBA}$ and then drop again between 2 and $3 \mathrm{pm}$. There is then a notable rise in the late afternoon, between 3 and $6 \mathrm{pm}$ reaching $75 \mathrm{dBA}$ at $5 \mathrm{pm}$. Decibel levels generally fall off during the remainder of the day, declining to around $40 \mathrm{dBA}$ by midnight.

The sound profile in the Huambocancha barrio varies considerably from hour to hour on Saturday. Decibel levels rise to a morning high of $67 \mathrm{dBA}$ at $8 \mathrm{am}$, then rise and fall between 5 and $10 \mathrm{dBA}$ throughout the remainder of the morning, reaching a daily high of $74 \mathrm{dBA}$ at $3 \mathrm{pm}$. Sound levels fall off again during the afternoon dropping to 44 $\mathrm{dBA}$ at $6 \mathrm{pm}$, but then fluctuate up and down again during the evening, finally settling at about $45 \mathrm{dBA}$ at $11 \mathrm{pm}$.

\section{Weekend Sound Profiles - Sunday}

Sound levels in the town's commercial section at the corner of Jr. Tarapacá and Jr. Lima vary considerably on Sunday (Fig 4). Early morning decibel levels are low, ranging between 50 and $60 \mathrm{dBA}$ until about 10 am when they rise to $70 \mathrm{dBA}$. Decibel levels vary throughout the remainder of the day between 60 and $70 \mathrm{dBA}$, but then peak at $75 \mathrm{dBA}$ at $8 \mathrm{pm}$. Sound levels fall off quickly after that, settling at around $40 \mathrm{dBA}$ between $11 \mathrm{pm}$ and midnight.

On the central plaza Sunday decibel levels display considerably less variation hour to hour. Early morning readings stand at about $55 \mathrm{dBA}$, then rise slowly but steadily throughout the morning reaching $65 \mathrm{dBA}$ by $1 \mathrm{pm}$. Sound levels remain at this level throughout most of the afternoon and begin to drop off at $6 \mathrm{pm}$. Decibel levels decline steadily throughout the evening dropping to between 40 and $45 \mathrm{dBA}$ at midnight.

Sunday sound patterns in the peripheral residential areas of the town are much more variable on an hour to hour basis than at the central plaza and also reach higher 
levels. On Jr. Cinco Esquinas daily decibel levels peak at 8 am at $77 \mathrm{dBA}$, dropping off slightly throughout the rest of the morning to about $53 \mathrm{dBA}$ at noon. Sound levels rise gently throughout the early afternoon, peaking at about 63 $\mathrm{dBA}$ at $3 \mathrm{pm}$ and then slowly declining to the mid-50s at 6 $\mathrm{pm}$. Decibel levels rise again in the early evening peaking at $65 \mathrm{dBA}$ at $8 \mathrm{pm}$ and then drop off to $45 \mathrm{dBA}$ by $11 \mathrm{pm}$.

In the Huambocancha barrio sound levels vary considerably during the morning, but portray a more consistent pattern in the afternoon. Decibel levels peak twice at $65 \mathrm{dBA}$ in the morning, at $9 \mathrm{am}$ and at noon. They then decline steeply at $1 \mathrm{pm}$ to $47 \mathrm{dBA}$. During the early afternoon decibel levels rise significantly, reaching a daytime high of $75 \mathrm{dBA}$ at $3 \mathrm{pm}$. Sound levels fall off more or less steadily throughout the afternoon and evening declining to about $43 \mathrm{dBA}$ at $11 \mathrm{pm}$.

\section{Conclusions}

Cajamarca is a comparatively quiet city. At no recording site did sound levels ever exceed $77 \mathrm{dBA}$, and even in the commercial center of the city at Jr. Tarapacá weekday sound levels averaged only about $70 \mathrm{dBA}$ throughout most of the day. Noise levels do vary somewhat between different parts of the city, with levels being slightly higher in the commercial center than in the residential areas or on the plaza de armas.

The characteristic patterns of spatial and temporal human activity in the the city are partially revealed in the sound profiles presented here. The sound profiles for the central plaza illustrate the constant movement and presence of people and vehicles there throughout the day and the week. These profiles also illustrate that during weekend afternoons decibel levels in the central plaza rise reflecting the increased socializing and strolling that occurs there by the city's residents. Indeed, throughout the week decibel levels are fairly constant in the plaza from the early morning well into the evening and it is only late in the evening, after $10 \mathrm{pm}$, that decibel levels drop off significantly. A similar pattern is evident in the commercial core of the city at Jr. Tarapacá where weekday and Saturday decibel levels show little variation between 7 am and $9 \mathrm{pm}$. During that time period decibel levels range no more than about $8 \mathrm{dBA}$. On both weekdays and Saturdays the sound profiles for Jr. Tarapacá portray a clear jump of about $5 \mathrm{dBA}$ at $10 \mathrm{am}$, the time when most commercial establishments open. Curiously however there is no clear decline in decibel levels during the 1 to $3 \mathrm{pm}$ midday meal time when most businesses close and workers and shoppers alike return home to eat.

Sound profiles in residential areas are somewhat more erratic than those from the urban core, but nonetheless they do reveal some consistent patterns. At the site at Jr. Cinco Esquinas for instance, both weekday and weekend profiles illustrate low decibel levels in the early morning hours which then rise rapidly through the early and midmorning hours. The weekday profile does reveal a modest
SUNDAY SOUND PROFILES
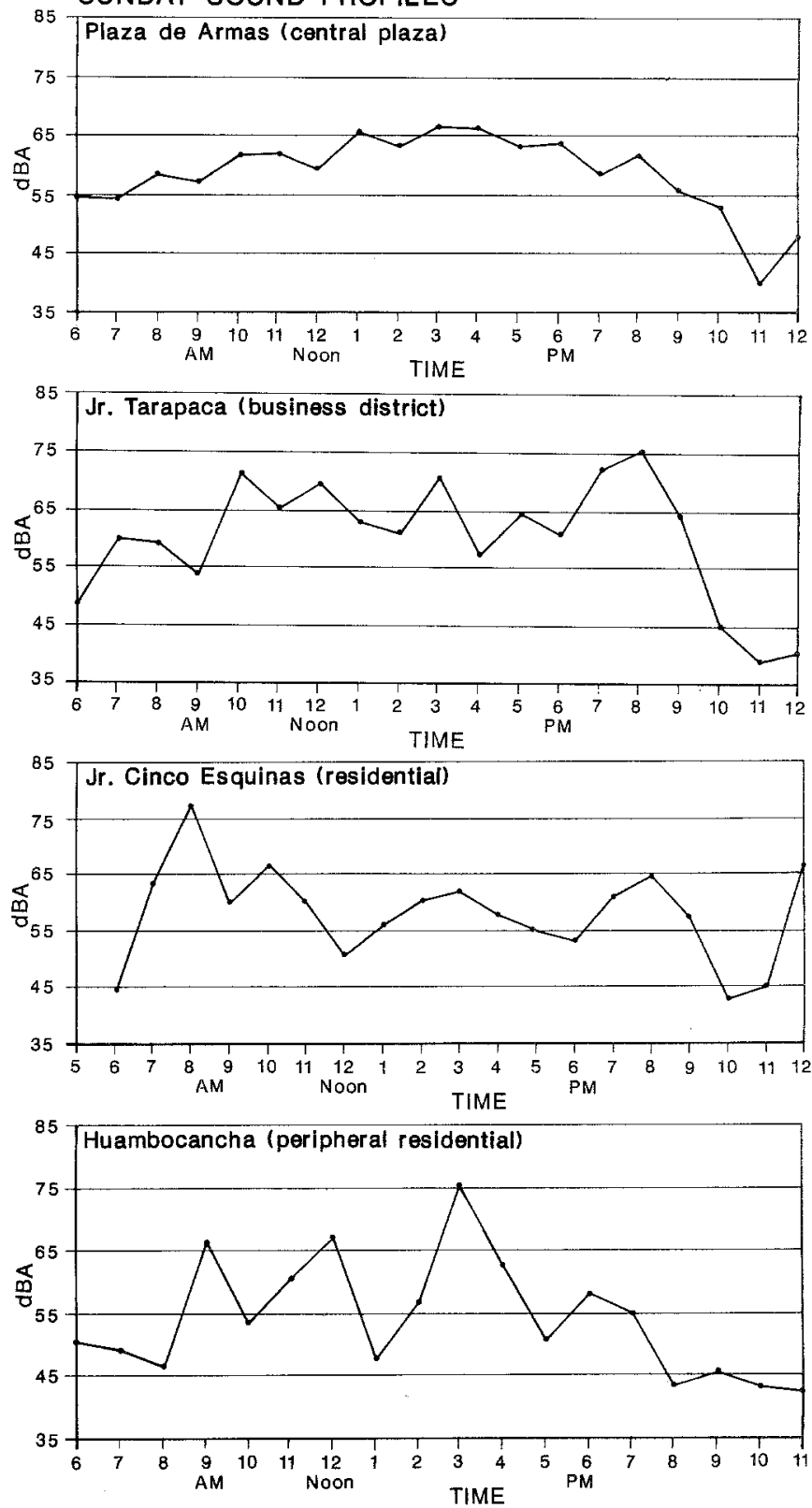

Fig 4 Sunday sound profiles, Cajamarca, Peru

decline in decibel levels at $2 \mathrm{pm}$ the time most residents are at home eating their midday meal and a slight peak at 6 pm when many return home from work, school, or other social activities. And, as residents conclude their daily activities and retire for the evening, decibel levels drop off steadily. Weekend sound profiles do not present such clear patterns, although decibel levels do rise consistently through the early morning hours and decline steadily during the evening. Saturday sound patterns during the day do offer some opportunities to correlate decibel levels with residential activity. The peak at 10 am reflects residents' 
shopping patterns and other activities related to the weekly Saturday market held in Cajamarca. The lowered decibel levels between 2 and $3 \mathrm{pm}$ correlate with the time most residents take their midday meal. The Sunday sound profile is more varied and less easily correlated with resident's activities, except that overall decibel levels are lower on Sunday than either the weekday or Saturday profiles reflecting a general decline in activities on that day and a slower pace for those that do occur.

In the peripheral barrio of Huambocancha, the sound profiles vary considerably from hour to hour and those patterns that exist are not easily correlated with typical daily routines. This may be explained by the barrio's development as a residential strip along the principal highway heading north out of Cajamarca. Thus, the sound from car and truck traffic which frequently travels the road could easily overshadow sound patterns created by local resident's activities.

The data presented in this study are limited. Only four sites were used to attempt to establish general patterns of sound levels throughout the city. Furthermore, the number of readings taken at each of the sites was relatively small. Thus, the data presented here can in no way be considered as definitive nor can the conclusions. Rather they must be considered as tentative and preliminary until further studies of the temporal and spatial variations in sound levels in Andean cities can be undertaken.

\section{Acknowledgements}

Thanks go to Fidel Chavez, Matthew Noble, Vern Harnapp, and Augusto Gandia who all provided assistance at various points in the execution of this research. The Department of Geography and Planning and the Dean's Office of Buchtel College of Arts and Sciences of the University of Akron both provided financial support that allowed completion of this paper.

Ugarte Chamorro, J.: Contaminación atmosférica en Lima. Universidad Nacional Frederico Villareal, Lima. Typescript. 9 pp., 1977.

Underwood, J.R.; Boodlal, L. S.: Traffic noise levels in a tropical environment. Transportation Planning and Technology 8: 87-99 (1983)
Noble, Allen G.; Dutt, K. Ashok; Venugopal, G.: Variations in noise

generation. Geografiska Annaler 67B(1): 15-19 (1985)

\section{References}

Noble, Allen G.: Noise pollution in selected Chinese and American cities. GeoJournal 4(6): 573-575 (1980)

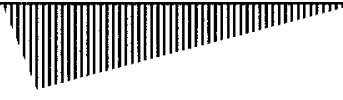

\section{Rule and Order}

\section{Dutch Planning Doctrine in the Twentieth Century}

\author{
by Andreas Faludi, Arnold van der Valk
}

GEOJOURNAL LIBRARY 28

This book is concerned with the strategic planning in the Netherlands. Although the Netherlands is stated to be a planner's paradise, it should be realized that it is one that is carefully constructed and maintained by the planners themselves. In discussing national planning, and in this framework provincial and local planning are also treated, the authors invoke a well-developed planning doctrine. This planning doctrine not only encompasses a definitive view of what the country should look like i.e. a distinct pattern of urban settlements, 'Randstad' enclosing the 'Green Heart' as well it addresses how government should attend to preserve the 'Green Heart' under increasing pressure.

By means of the 'planning doctrine' planners are stimulating public support. This book comprises the origin and establishment of the 'doctrine' up to and including the Fourth Report on National Physical Planning.

This book will be of interest to scientists, researchers and practitioners in urban, regional and strategic planning, urban and social history, social geography, public administration and policy sciences.

$1994,288 \mathrm{pp}$.

Hardbound \$99.50/Dfl. $170.00 / £ 68.00$

ISBN 0-7923-2619-9

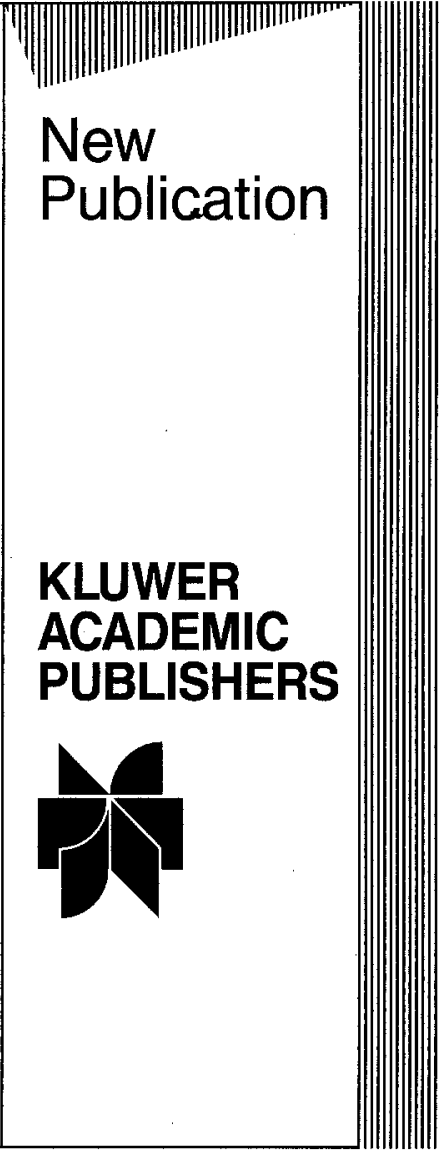

